\title{
The Impact of National Culture on Knowledge Sharing: The Moderate Role of Organizational Culture
}

\author{
Saleh Abdullah Al Thnayan \\ salehalthnayan@gmail.com
}

Areej Abdulrahman Alarifi

areejalarifi@yahoo.com

Faculty of Economics and Administration

King Abdulaziz University

Jeddah, Kingdom of Saudi Arabia

\begin{abstract}
Purpose: Examine the impact of national culture based on Hofstede's concept of cultural dimensions on knowledge sharing and the moderate role of the organizational factors as success factors.

Design | methodology| approach: The descriptive and inferential approach relying on a simple random sample among local and international employees working in Saudi Arabian Military Industries (SAMI) company. An electronic questionnaire distributed for this purpose.

Findings: Collectivism, Femininity, $L O$, and SR are positively impact on $K S$, while $P D, I, M, \cup A$, SO, and $I D$ are negatively impact the KS. Moreover, OC play a moderate role as success factor to maximize the advantage of $P D, C, F, L O$ and SR and minimize the impact of I, M, UA, SO and ID on KS. In addition, the index of six national cultural dimensions of the sample understudy was compared to original Hofstede index and resulted on almost the same values.

Originality / value: There are a few studies that examine the effect of the indulgence/self-restraint dimension. Moreover, most studies focus on single culture and there are a few studies that compare the national culture between two or more countries. Finally, there is no study has been conducted to examine the moderate role of organizational culture in this relationship. All of these aspects give uniqueness to this study and encourage to fill-up those gaps.
\end{abstract}

Keywords: Power Distance (PD), Uncertainty Avoidance (UA), Long-term Orientation (LO), Shortterm Orientation (SO), Self-restraint (SR), Individualism / Collectivism (IC), Masculinity / Femininity (MF), Uncertainty Avoidance (UA), Long-term / short-term orientation (LSO), Indulgence / Self-restraint (ISR), Knowledge Sharing (KS), Organizational Culture (OC).

\section{Introduction}

A study of the impact of national culture on organizational learning and knowledge management is becoming a subject for interdisciplinary research (Janićijević, 2016). The growing importance of organizational learning as a source of sustainable competitive advantage, and globalization of business and run-in multicultural contexts are the two reasons behind that (Reinhardt et al., 2003). Due to this factor, the need to know about different national cultures is growing in importance for effective organization management (Hofstede, 2001).

Several researchers have identified the basic dimensions that comprise diverse national cultures (Schwortz, 1992; Trompenears, 1994; Hall \& Hall, 1990; Javiden et al. 2006). The most important dimensions * This article was submitted in September 2021, and accepted for publishing in November 2021.

(c) Arab Administrative Development Organization- League of Arab States, 2022, pp 429-448،

DOI: 10.21608/aja.2021.94558.1151 
of national cultures were studied and described by Hofstede (2001), by identifying four basic dimensions discriminating national cultures: Power Distance (PD), Uncertainty Avoidance (UA), Individualism / Collectivism (IC) and Masculinity / Femininity (MF). A few years later, Hofstede, (2001) adds a fifth dimension, Long-term / short-term orientation (LSO), to discuss aspects of values that were not covered in the original paradigm (Hofstede, 2005). Five years later, Hofstede, (2010) added a sixth dimension, Indulgence / Self-Restraint (ISR) (Hofstede, 2010).

Many papers investigate the effect of national cultures on knowledge sharing (Al Hawamdeh and Al Qatamin, 2021; Hussien and Khedr, 2021; Evans, et al., 2014; Yu, 2014; Witherspoon et al., 2013; Engelen, et al., 2012; Fathi et al., 2011; Wang et al., 2011; Akar \& Eturk, 2010; Homburg, et al., 2007; Smeth et al., 2005; House, et al., 2004; Ford and Chan, 2003; Nahapet and Ghushal, 1998; Eramili, 1996 Bates et al., 1995; Bochner and Hesketh, 1994). However, there are a few studies that examine the effect of the ISR dimension (Hofstede, 2010). In addition, most of these studies focus on single culture and there are a few studies that compare the national culture between two or more countries (Hussien and Khedr, 2021). Finally, based on reviewing the literature, there is lack of study has been conducted to examine the moderate role of organizational culture in this relationship. All of these aspects give uniqueness to this study and encourage to fill-up those gaps.

This paper aims to examine the influences of national culture based on Hofstede's concept of cultural dimensions on the knowledge sharing and the moderate role of the organizational factors as success factors that would positively affect the relationship between these national cultures and knowledge sharing by maximizing the desired national culture dimensions and minimize the effect of the undesired dimensions. The descriptive and inferential approach used to work toward this goal, relying on a simple random sample among local and international employees working in Saudi Arabian Military Industries (SAMI) company. An electronic questionnaire distributed for this purpose.

\section{LITERATURE REVIEW}

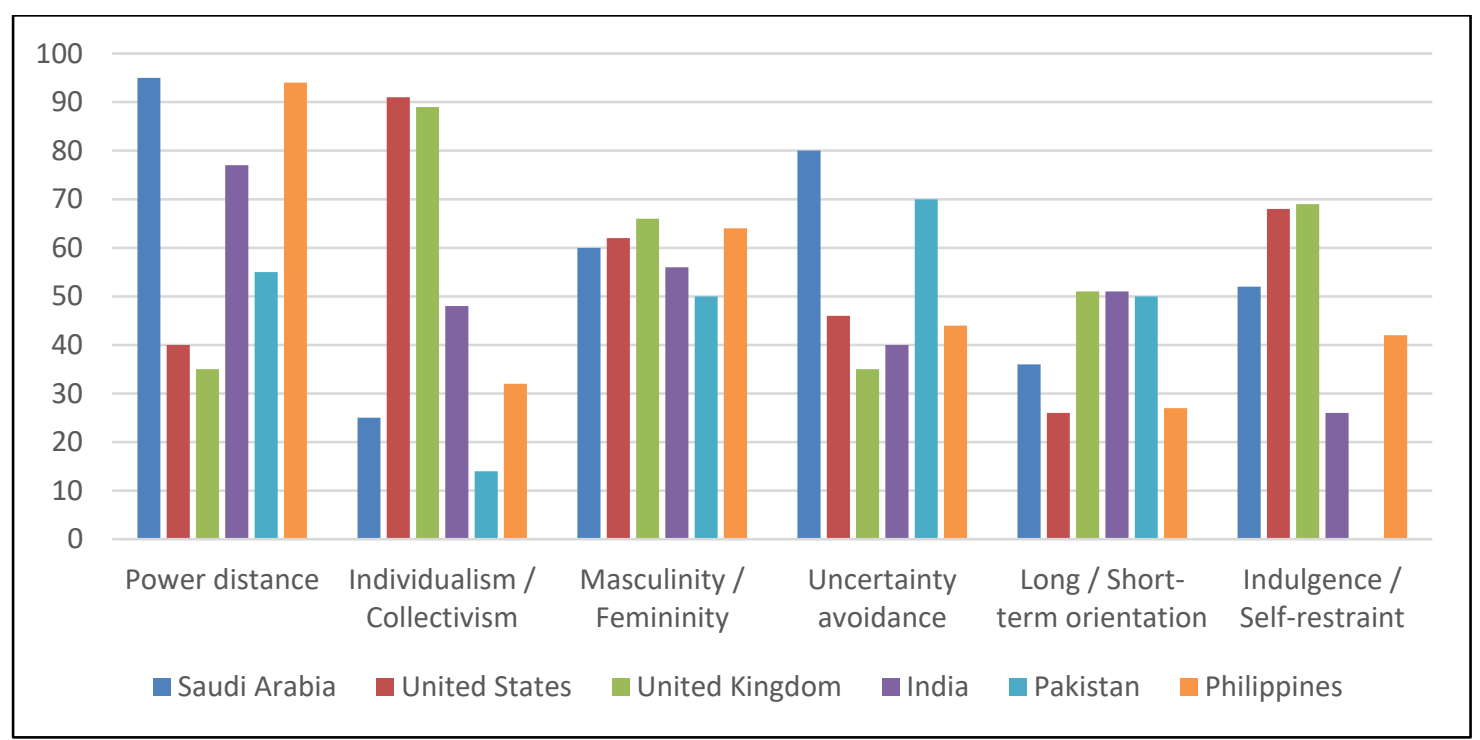

Source: www.hofstede-insights.com.

Figure 1. Hofstede Index for Nationalities Understudy

\section{Power Distance and Knowledge Sharing}

PD is "the extent to which less powerful peoples of a society expect and accept that power is being unequally distributed" (Hofstede, 2001). A high PD indicates the presence of a relatively bureaucratic social 
system (Deshpande and Farley, 1999), as well as a high level of status consciousness and a steep hierarchical orientation (Sinha \& Sinha, 1990). According to (Tihanyi et al., 2005; Mihet, 2013), the higher the distance in organizations, the more formalized and hierarchical they are, the tighter control by management and less horizontal communication they have (Jones, et al., 2000), and the less room for employees participation they have within their organizations (Efrat, 2014), where managers rely on rules and orders, while employees look to and guided by their managers for instruction about what and how to do the tasks (Hauff et al., 2015; Robert et al., 2000). The symptoms of high PD may appear in form of a pyramidal organizational structure, high monitoring, strict control, and a fear of talking honestly. All of these symptoms have a negative effect on knowledge sharing (Wang et al., 2011; Evans et al., 2014). There are three reasons behind the hampering of high PD to knowledge sharing: power inequality undermines the environment of knowledge sharing, demotivation to share knowledge by less powerful people because of autocratic leadership and centralization of authority, and asymmetry of information (Jang et al., 2016). As per Hofstede (2021), Saudi culture has the highest PD compared to the others cultures understudy (95), followed by Philippines (94), then India (77). Pakistan is relatively in the middle (55), while the least two countries are USA (40), then UK (35), which is the lowest culture in this dimension.

\section{H1: High Power Distance Has a Negative Impact on Knowledge Sharing.}

\section{Individualism-collectivism and Knowledge Sharing}

IC relates to how much group thinking and practicing takes precedence over individual thinking and practicing. (Efrat, 2014). The pivotal difference between individualism and collectivism related to the assumption of personal responsibility for one's own fate; Individualism holds each person solely responsible for himself and his family, whereas collectivism holds the collective accountable for each individual. It can be argued that collectivism has a positive impact on knowledge sharing, while individualism has a negative impact on knowledge sharing. Witherspoon et al. (2013) assert that in a collectivism culture, instead of an individualism culture, it is incredibly simple to promote knowledge sharing. There are two reasons behind that.

First, cooperation and teamwork are enhanced by collectivism (Chen et al., 1998) since it is assumed that people from collectivist cultures value collective interests over individual interests (Witherspoon et al., 2013). Nahapiet \& Ghoshal (1998) indicated that a cooperative environment makes knowledge more accessible and motivates people to exchange it. Furthermore, teamwork enables knowledge disclosure and is essential for creativity effectiveness (Wagner, 1995). Collectivism promote knowledge sharing behavior (Fathi et al., 2011), members readiness to share knowledge (Yu, 2014), and positively impact knowledge creation in the organization (Wiang et al., 2011). As a result of its collectivist nature, place a greater emphasis on the group would take place, and therefore have a positive impact on the OL process (Qin et al., 2011).

Studies on the eastern cultures assert that a collectivist culture creates greater integration at inter-functional level in an organization, along with and soft information flow and learning (Engelen, et al., 2012; Homburg, et al., 2007; House, et al., 2004). Additionally, Olsen, et al. (2001) assert that members and groups of organizations with collectivist cultures can discover more about the industry and improve their skills and performance.

Individualism, in contrast, reflects the work on personal goals and willingness to stand against members of the in-group (Wagnar, 1995). Consequently, members from individualist cultures rarely share and interchange knowledge with other employees of the organization, and therefore limiting organizational ability to share knowledge (Bochner \& Hesketh, 1994). Individualism considers that personal value is more significant than community objectives (Chin et al., 1998), as a result, they don't recognize the value in the knowledge share and combination process (Nahapet \& Ghushal, 1998; Smeth et al., 2005). In conclusion, collectivism recognizes the value of knowledge exchange and combination and speeds up these processes, 
whereas individualism prioritizes individual goals over organizational objectives and hinders knowledge interchange and combination.

As a result, collectivism makes a significant contribution to knowledge sharing because it encouraging knowledge interchange and combination (Nahapet \& Ghushal, 1998; Smeth et al., 2005). Second, collectivism prefers collaboration to obtain value for the community, and it accepts the value derived from the process of knowledge interchange and combination (Bates et al., 1995).

As per Hofstede (2021), USA, and UK have the highest individualism culture compared to the others cultures understudy (91 \& 89) respectively, followed by India (48), which is relatively in the middle of this dimension. Philippine (32), Saudi Arabia (25), and Pakistan (14) are the lowest culture in this dimension. This level also offer indication also for collectivism; Pakistan is the highest country in collectivism followed by Saudi Arabia, Philippine, India, UK, and finally USA.

\section{H2 : Individualism Has a Negative Impact on Knowledge Sharing.}

$\mathrm{H}_{\mathrm{b}}$ : Collectivism Has a Positive Impact on Knowledge Sharing.

\section{Masculinity-femininity and Knowledge Sharing}

MF indicate to the style of gender domination in a society, the distribution of roles between men and women, reveals society's attitude toward doing and being (Hofstede, 2001). According to Efrat (2014), more masculine cultures show imbalances between men and women roles in society. High score (Masculine) points out that the community will be guided by competition, achievement and successfulness, as it characterized by the winner/best in field. Various Studies illustrate that highly masculine cultures are described by ego, higher achievement, and taking risks (Hofstede, 2010; Cantwell, 2000). According to Evans, et al. (2014), highly masculine cultures act as an obstacle to knowledge sharing and seeking because it gives more significance to the competitiveness which results in knowledge hoarding. Ford and Chan (2003) also claimed that cultures with a high level of masculinity might have struggles sharing knowledge with others who have competition with them if individuals are competitive. Many researchers assert that people hide knowledge, particularly tacit knowledge, notably when there is high competition between them in an organization. This is related to masculinity's cultural dimension, as status and power are prevalent values in masculine cultures and People may fear losing their power if they share their valuable knowledge. Because of the need for high performance and successfulness, social appreciation, and financial earnings, member from masculinity culture is more willing to learn about their business environment, more innovative, and are high performers. Moreover, a high score (Masculine) points out that the society will be guided by competition, performance and successfulness, as it characterized by the winner / best in field (Janićijević, 2016). In contrast, a low score (Feminine) means that the predominant values in community are taking care for others and life quality (Hofstede, 2010). A Feminine community is one where life quality is the mark of success and standing out from the crowd is not preferable (Hofstede, 2001), which encourage organizational learning processes and positively affect knowledge sharing.

\section{H3: Masculinity Has a Negative Impact on Knowledge Sharing.}

\section{$\mathrm{H} 3_{b}$ : Femininity Has a Positive Impact on Knowledge Sharing.}

As per Hofstede (2021), UK has the highest level in Masculinity (66), followed by Philippine (64), then USA (62), Saudi Arabia (60), while India and Pakistan have the lowest level (65 \& 50) respectively. These levels also offer indication also for femininity; Pakistan are the highest country in femininity followed by India, Saudi Arabia, USA, Philippine, and finally UK. 


\section{Uncertainty Avoidance and Knowledge Sharing}

UA reveals how concerned members of a society are about ambiguous circumstances and the approaches they use to cope with them (Troy, et al., 2008). UA is weak in organizations that accept uncertainty, take more risks, tolerate different opinions and behaviors, and open to challenge current routines by creating new knowledge (Akar \& Eturk, 2010). In contrast, organizations with a high degree of UA require predictability, applying similar action, and a strong preference for codification (Eramili, 1996), so they are more willing to keep the current knowledge base stable instead of pursuing new knowledge (Bochner \& Hesketh, 1994). As a result, organizations with a low level of UA are more motivated to create new knowledge, improve their knowledge creation capabilities, and share knowledge. Furthermore, organizations' desired to try out novel ideas and take risks has a big effect on knowledge exchange and combination (Akar \& Eturk, 2010). Employees in organizations with a low level of UA are motivated to test and share their knowledge and ideas. Organizations that dislike taking risks and experimenting, on the other hand, are opposed to sharing and combining knowledge and ideas (Smeth et al., 2005). As a result, organizations are pushed away from improving their knowledge sharing capabilities by UA. Organizations with a high-uncertainty culture, according to Dimitratos et al. (2011), commonly have regulations and procedures that classify and monitor their organizational duties and rights. Members are reluctant to take risks, hesitating to use to solve problems creatively, restrictive, persistent to change (Efrat, 2014; Garrett, et al., 2006), and have low innovation level as a result of their relying on rules and regulations (House et al., 2004). Therefore, UA has a negative influence on the knowledge sharing (Wang et al., 2011).

\section{H4: UA Has a Negative Impact on Knowledge Sharing.}

As per Hofstede (2021), Saudi Arabia has the highest UA culture compared to the others cultures understudy (80), Pakistan is the second (70). The rest cultures are tend to be not avoiding uncertainty since their levels are under the middle; USA (46), Philippine (44), India (40), and finally UK (35).

\section{Long-term / Short-term Orientation and Knowledge Sharing}

LSO is the extent to which a society prioritizes the future orientated perspective instead of the conventional historic or short-term perspective. A long-term orientation is characterized by persistence, following a specific ordering pattern, and a sense of shame. It includes investment in the future (Hofstede, 2005). The opposite is short-term orientation that promotes personal steadiness and stability, and respect for tradition. Focus is on happiness rather than peace of mind.

This dimension consists of aspects with two poles, each with a different set of values. Long-term-orientation or high confucian dynamism scores indicate a proclivity for thinking about the future. People in a culture with high long-term-orientation or high confusion dynamism scores are more likely to value perseverance, placing an order for relationships based on status, thrifty values, and having a feeling of shame. In contrast, Members of short-term orientation or low confucian dynamism scores respect the relative importance of the past and present, such as personal constancy and steadiness, saving face, respect for custom and tradition, and reciprocation of greetings, favors, and gifts (Hofstede, 2010).

Long-term objectives are more motivating for members of a long-term-oriented culture. The long-term orientation dimension, according to Ford and Chan (2003), explains how members of a culture are motivated to work toward long-term objectives. Because knowledge sharing is a long-term process with a high payoff, a long-term-oriented culture is more able to practice knowledge sharing. According to Evans, et al (2014), national culture's short-term orientation can negatively affect knowledge sharing and creation because of fear of shame or loss of face, high respect for coms and traditions, and focus on quick results in such cultures.

\section{H5 : Long-term Orientation Has a Positive Impact on Knowledge Sharing.}

H5: Short-term Orientation Has a Negative Impact on Knowledge Sharing. 
As per Hofstede (2021), UK (51), India (51), and Pakistan (50) are moderate in this dimension, while Saudi cultures tend to be short-term orientation (36), and Philippine and USA have the shortest-term oriented culture compared to the others cultures understudy since their levels are ( $27 \& 26)$ respectively.

\section{Indulgence / Self-restraint and Knowledge Sharing}

The concept of indulgence symbolizes a society that is somewhat tolerant of the human drives' natural wants and needs related to enjoying life and having fun. Self-Restraint, on the other hand, stands for a society that prohibits an open gratification of desires and regulates it through strict social norms and traits (Hofstede, 2010).

The ISR dimension represents a culture that allows essential and normal human wants and needs related to enjoying life and having fun to be satisfied, versus a culture that restricts desire satisfaction through rigid social roles (Hofstede, 2010). In other phrases, cultures with high indulgence level place a higher value on enjoyment and welfare life than cultures with low indulgence scores, which place a greater emphasis on suppressing satisfaction and indulgence and regulate culture's behavior and attitudes through tighter social rules. In business, this means that people in more restraint cultures are more conservative in their business practices, are more pessimistic, and take fewer risks.

As per Hofstede (2021), UK, and USA have the highest Indulgence culture compared to the others cultures understudy (69 \& 68) respectively, followed by Saudi cultures (52), which is relatively in the middle of this dimension between Indulgence and Self-restraint. Philippine (42) tend to be Self-restraint cultures. While there is no data available for Pakistan, India is the most Self-restraint cultures in this study (26).

The relative level of this dimension for countries under study is almost parallel to the IC dimension. Given the characteristics of this dimension, and while there is no study measuring the effect of this dimension on knowledge sharing, and based on the impact of IC dimension, it can be argued that Indulgence has a negative impact on knowledge sharing while self-restraint has a positive impact. The following hypotheses are formulated:

\section{H6: Indulgence Has a Negative Impact on Knowledge Sharing. \\ $\mathrm{H6}_{\mathrm{b}}$ : Self-restraint Has a Positive Impact on Knowledge Sharing.}

\section{Organizational Culture and Knowledge Sharing: Critical Success Factors}

Organizational culture could be described as the essential, and collective propositions that an organization learns when dealing with the environment and finding solutions of exterior modifications and interior integrations, which are taught to new employees as the right path to solving those problems (Park et al., 2004). Each organization has its own culture that evolves over time to represent the organization's identity in both visible and invisible dimensions. The organization's core values, philosophy, and mission representing the culture's visible dimension, whereas the unstated series of values that drive employees' behavior and perspectives throughout the organization representing the culture's invisible dimension (McDermott \& O'Dell, 2001). Six major factors make up organizational culture: information systems, confidence, individuals, procedure, leadership, employees' communication, incentives system, and organizational structure (Gupta \& Govindarajan, 2000). The factors that this study focus on are those that were heavily highlighted in the previous studies as success factors for knowledge sharing, which are Confidence, employees' communication, information systems, incentives system, and organizational structure.

Knowledge sharing is an essential component of the Knowledge management process (Dalkir, 2017). Knowledge sharing is an action where certain people, friends, peers, families, communities, or organizations exchange knowledge including information, skills, or experiences (Ipe, 2003; Liebowitz, 1999; Serban \& Luan, 2002; Liebowitz, 1999). Humans share their knowledge in a variety of ways, including discussions, 
conferences, learning courses, training, video files, and other methods of communication. Organizations realize that knowledge is an important intangible asset for gaining and maintaining competitive advantages (Millar \& Shamse, 1996). Knowledge management systems are commonly used to support the activities of knowledge sharing. Nevertheless, technology is just one of several factors that influence knowledge sharing at the organizational level. Other factors including organizational culture, confidence, and rewards (Cabrera \& Cabrera, 2002). Because some people are hesitant to share their knowledge with their colleagues and other parties among the organization due to different cultural factors, these factors are considered as significant challenges in the area of knowledge management generally and knowledge sharing specifically (Ciborra \& Patriotta, 1998).

Interpersonal confidence, or confidence between fellow employees, is a critical component of organizational culture, and it is thought to have a significant impact on knowledge sharing (AlAlawi et al., 2007). Interpersonal confidence is described as an individual's or a collective's belief in the anticipation of another person's or group's words or actions (Politis, 2003). In order to respond honestly and share their knowledge, team members require the presence of confidence (Gruenfeld et al., 1996).

Employees' communication refers to humanitarian interaction that takes place through verbal discussions and body language or nonverbal communication. The presence of social networking in the organization greatly enhances humanitarian interaction. These types of communication are critical for enhancing knowledge sharing (Smeth \& Rupp, 2002).

Information systems are an arrangement of people, data, and procedures that work together to facilitate organizational day-to-day operations, solving issues, and decision-making (Whiten et al., 2001). Organizations use various information systems to encourage knowledge-sharing by generating or acquiring knowledge warehouses, where employees physically or digitally share experience and other employees have access to the shared knowledge (Connelly \& Kelloway, 2003).

Employees need strong incentives to share knowledge, according to Syed-Ikhsan \& Rowland (2004). It's unreasonable to expect all staff are willing to easily share their knowledge without thinking about what they might gain or lose as a consequence of their actions. When designing incentives systems, organizations must recognize the significance of cooperation and sharing best practices (AlAlawi et al., 2007). The objective is to design an incentive system that promotes and even reward information sharing and horizontal communication. Incentives should rely on group performance instead of individual performance (Goh, 2002).

Complex layers and lines of responsibility are characteristic of traditional organizational structures with predefined details of information reporting methods. Most organizations today are aware of the drawbacks of bureaucratic hierarchy in terms of slowing down processes and restricting data flow. Furthermore, such methods frequently take a long time to accomplish in order for knowledge to filter through all levels (AlAlawi et al., 2007). Knowledge sharing thrives when organizational structures that help to facilitate the flow of information among fewer divisional boundaries (Syed-Ikhsan and Rowland, 2004).

With highly support in literature to the impact of organizational culture on knowledge sharing, it can be argued that the organizational culture would minimize the negative impact of national culture on knowledge sharing and maximize their impact as well. Therefore, the following hypothesis are formulated:

H7: Organizational Culture Moderate the Relationship between National Cultures and Knowledge Sharing.

\section{CONCEPTUAL FRAMEWORK}

Figure (2) shows perceived relationship between the variables, where National culture in its six measures (PD, IC, MF, UA, LSO, and ISR) is considered as independent variables, knowledge sharing is the dependent variable, and the organizational culture is the moderate variable. 


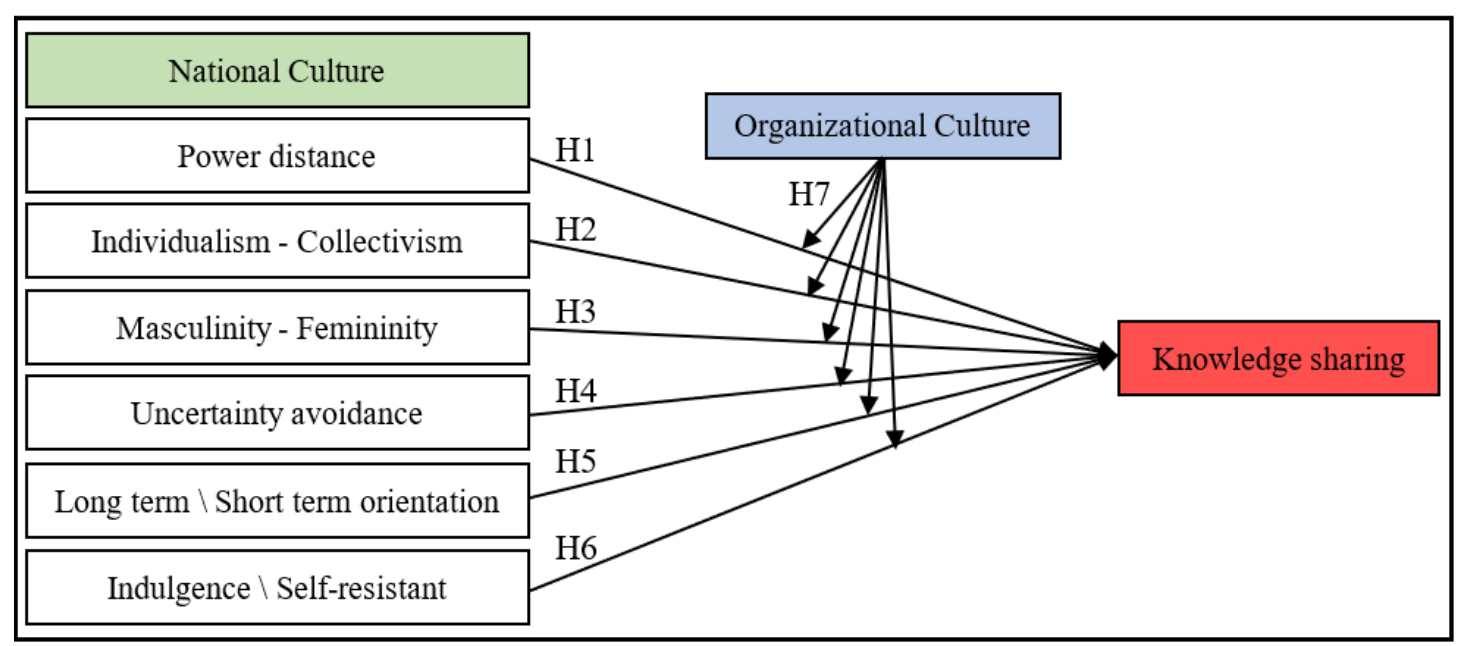

Figure 2. Conceptual Framework

\section{Context of the Study}

The Saudi Military Industries Corporation (SAMI) was established on May 17, 2017, and it is the new national entity in the military industries sector. The company represents a component of the Saudi Vision 2030, and is also considered a sustainable platform for providing military products and services in the Kingdom (Sami, 2021). The company's direct contribution to the Kingdom's GDP is more than 14 billion SAR, and the company will allocate 6 billion SAR for investment in research and development operations. The company has about 3 thousand employees from different nationalities: USA, the UK, India, Pakistan, France, Philippines, in addition to local employees (SAMI, 2021). This cultural diversity along with the company's interest in research and development makes it important to study the impact of the dimensions of national culture on the knowledge sharing in addition to knowing the main factors that will maximize the benefit of this cultural diversity and reduce its disadvantages to make the organizational learning process more effective.

As a part of Saudi Vision (2030), The Saudi government announced the suspension of contracting with any foreign commercial company or establishment with a regional headquarters in the region outside the Kingdom, starting from January (2024). This orientation comes in line with the announcement of the strategic goals of the Kingdom's capital, Riyadh (2030), during the recently held Future Investment Initiative Forum, during which 24 global companies intend to move their regional headquarters to Riyadh (SPA, 2021). This would lead to increasing the cultural diversity in the labor market generally and specifically within many large multinational companies that intend to expand their operations in Saudi Arabia. Moreover, it encourages to the study of these diversities and their impact on knowledge sharing as an essential aspect of Knowledge management, which now considered the most important competitive advantage for many organizations (Zaim et al., 2018). Therefore, Given the research gap discussed, this study, this study provides the managers of these organizations, practitioners, and researcher, the most updated and latest finding of variables understudy and the relationship between them. In addition, this study will provide scientific evidence of the success factors that would help them to develop the knowledge sharing processes in order to improve the overall organizational performance.

\section{METHODOLOGY}

This research relies on a quantitative approach using the questionnaire as a primary data collection method. Then, descriptive and inferential analysis was taken place using SPSS version 21.0. The target population of this study is all employees worked at Saudi Military Industrial (SAMI) company.

The unit of analysis is the employee worked at Saudi Military Industrial (SAMI) company. The questionnaires distributed electronically among those employees using a simple random sampling, which give each element the same opportunity to participate in questionnaire. 
There are Six nationalities worked in SAMI (Saudi, American, British, Pakistan, India, and Philippines). The total number of employees is 3000 students. Based on Israel, Glenn D. (1992), the optimum sample size for this study was calculated and resulted in 352 responses. Due to formal support for this study, the returned usable questionnaires were 352 .

Given a deductive approach of the study, most of the questionnaire items in this research were adapted from published studies (Table 1). Since these studies were mainly performed in different settings, some changes were made using local words such as sentence restructuring.

An introduction to the study was included in the questionnaire, which notified participants the study's purpose. Participants was given the option of participating voluntarily, and they notified that their responses are private and confidential. Both an English and an Arabic edition of the questionnaire were formed.

Table No. (1)

Published Studies in Which the Questionnaire Items Were Adapted From

\begin{tabular}{ccl}
\hline \multicolumn{2}{c}{ Construct Items } & \multicolumn{1}{c}{ Reference } \\
\hline PD & 3 & Wang et al., (2011) \\
\hline IC & 3 & Wang et al., (2011) \\
\hline MF & 3 & Miller \& Karakowsky, (2005) \\
\hline UA & 3 & Wang et al., (2011) \\
\hline LSO & 3 & Bearden et al., (2006) \\
\hline ISR & 3 & Matsudaira et al., (2008) \\
\hline OC & 6 & Al-Alawi et al., (2007) \\
\hline KS & 3 & Al-Alawi et al., (2007) \\
\hline
\end{tabular}

\section{RESULTS AND DATA ANALYSIS}

\section{Reliability and Validity Test}

Although measures in this study are mostly adapted from published articles, the risk to reliability and validity threat still exists since they have been conducted in a different context. In this regard, a pilot survey was implemented to 30 respondents to verify the reliability and validity of the questionnaire. Moreover, six constructs (PD, IC, MF, UA, LSO, ISR, KS, and OC) were operationalized to reduce their abstract concepts into observable and measurable elements. One of the methods to measure reliability is the Cronbach alpha coefficient. When calculating the Cronbach alpha, all build's reliability coefficients were in the range of 0.721 to 0.829 matching the minimum cut-off value (Sekaran, 2003) and reflect the instrument's consistency. To determine the questionnaire validity, the researchers used a correlation method to compare item correlation with the total item (Guilford, 1954). Table 2 reveal that all reliability and validity were statistically significant.

Table No. (2)

Measuring Reliability and Validity of the Questionnaire

\begin{tabular}{|c|c|c|c|c|}
\hline Dimension & Name & Items & $\begin{array}{c}\text { Cronbach } \\
\text { Alpha }\end{array}$ & $\begin{array}{c}\text { Total } \\
\text { Correlation } \\
\end{array}$ \\
\hline \multirow{3}{*}{$\begin{array}{l}\text { Power } \\
\text { Distance }\end{array}$} & PD1 & $\begin{array}{l}\text { I believed that hierarchical line in my organization should be very distinct and } \\
\text { not allowed to be bypassed. }\end{array}$ & \multirow{3}{*}{0.775} & $0.617^{* *}$ \\
\hline & PD2 & $\begin{array}{l}\text { The juniors should not allow to against the superior, and they must follow the } \\
\text { will of the superior. }\end{array}$ & & $0.628^{* *}$ \\
\hline & PD3 & The superior should have the last word, and the juniors should not discuss with them freely. & & $0.719 * *$ \\
\hline \multirow{3}{*}{$\begin{array}{c}\text { Individualism } \\
- \\
\text { Collectivism }\end{array}$} & IC1 & I Believe that my company should emphasizes cooperation and collectivism. & \multirow{3}{*}{0.823} & $0.760^{* *}$ \\
\hline & $\mathrm{IC} 2$ & $\begin{array}{l}\text { I Believe that my company should encourages jointly responsible for the suc- } \\
\text { cesses and failures. }\end{array}$ & & $0.836^{* *}$ \\
\hline & IC 3 & I prefer close cooperation with colleagues over working independently. & & $0.867 * *$ \\
\hline \multirow{3}{*}{$\begin{array}{l}\text { Masculinity- } \\
\text { Femininity }\end{array}$} & MF1 & The relationship with my coworkers should be built on competitiveness not cooperation. & \multirow{3}{*}{0.749} & $0.798^{* *}$ \\
\hline & MF2 & $\begin{array}{l}\text { I believe that caring for my coworkers is the most important success factor in } \\
\text { my business life. }\end{array}$ & & $0.784^{* *}$ \\
\hline & MF3 & Standing out from my coworkers is not admirable. & & $0.651^{* *}$ \\
\hline \multirow{3}{*}{$\begin{array}{l}\text { Uncertainty } \\
\text { Avoidance }\end{array}$} & UA1 & $\begin{array}{l}\text { I believe that managers encourage the development of innovative strategies, } \\
\text { knowing well that some will fail. }\end{array}$ & \multirow{3}{*}{0.829} & $0.821^{* *}$ \\
\hline & UA2 & I believe that a change in market creates a positive opportunity for us. & & $0.687^{* *}$ \\
\hline & UA3 & I have a strong preference for high-risk projects with chances of high return. & & $0.784^{* *}$ \\
\hline
\end{tabular}




\begin{tabular}{|c|c|c|c|}
\hline Dimension & Items & $\begin{array}{c}\text { Cronbach } \\
\text { Alpha }\end{array}$ & $\begin{array}{c}\text { Total } \\
\text { Correlation } \\
\end{array}$ \\
\hline \multirow{3}{*}{\begin{tabular}{l} 
Long \} $\\
{\text { Short-term }} \\
{\text { Orientation }}$ & LSO1 Respect for tradition is important to me. & \multirow{3}{*}{0.824} & $0.620^{* *}$ \\
\hline & LSO2 I am constantly planning for the long term. & & $0.859 * *$ \\
\hline & LSO3 I value a strong link to my past. & & $0.849^{* *}$ \\
\hline \multirow{3}{*}{$\begin{array}{l}\text { Indulgence } \\
\text { Self-restraint }\end{array}$} & $\begin{array}{l}\text { ISR1 If I have a strong opposite view, I can keep it to myself and not share it with } \\
\text { people around me. }\end{array}$ & \multirow{3}{*}{0.821} & $0.762^{* *}$ \\
\hline & ISR2 In my business life, I am always optimistic for the future. & & $0.830^{* *}$ \\
\hline & ISR3 I like enjoyment and welfare practices even if it violates the social rules. & & $0.793^{* *}$ \\
\hline \multirow{6}{*}{$\begin{array}{l}\text { Organizational } \\
\text { Culture }\end{array}$} & OC1 Certain tasks are accomplished through teamwork and collaboration between employees. & \multirow{6}{*}{0.732} & $0.745^{* *}$ \\
\hline & OC2 Coworkers commonly exchange their knowledge and experience while working. & & $0.792 * *$ \\
\hline & $\begin{array}{l}\text { OC3 } \begin{array}{l}\text { Most of my colleagues are people whom I know well and thus are considered } \\
\text { trustworthy. }\end{array} \\
\end{array}$ & & $0.770^{* *}$ \\
\hline & OC4 The technological tools available at the organization for sharing knowledge are effective. & & $0.762^{* *}$ \\
\hline & $\begin{array}{l}\text { OC5 The knowledge sharing rewards available are effective in motivating staff to } \\
\text { spread their knowledge. }\end{array}$ & & $0.812^{* *}$ \\
\hline & OC6 Workers actively participate in the process of decision making. & & $0.835^{* *}$ \\
\hline \multirow{3}{*}{$\begin{array}{l}\text { Knowledge } \\
\text { Sharing }\end{array}$} & $\begin{array}{l}\text { KS1 The problem of people hoarding (keeping) knowledge does not exist and most } \\
\text { staff members are willing to share their knowledge freely. }\end{array}$ & \multirow{3}{*}{0.721} & $0.754^{* *}$ \\
\hline & KS2 I feel comfortable sharing my knowledge with my colleagues and workers. & & $0.743^{* *}$ \\
\hline & KS3 My organization encourage all staff to share their knowledge. & & $0.710^{* *}$ \\
\hline
\end{tabular}}
\end{tabular}

** P-value $<0.001$

\section{Descriptive Statistics of Demographic Data}

Descriptive statistical analysis displays the socio-demographic characteristics of the sample (Table 3).

Table No. (3)

\section{Descriptive Statistics of Demographic Data}

\begin{tabular}{lcc}
\hline \multicolumn{3}{c}{ Number Percentage } \\
\hline \multicolumn{3}{c}{ Age } \\
\hline $18-25$ & 46 & $13.1 \%$ \\
\hline $26-35$ & 74 & $21.0 \%$ \\
\hline $36-45$ & 160 & $45.5 \%$ \\
\hline $\begin{array}{c}\text { More than } \\
45.00\end{array}$ & 72 & $20.4 \%$ \\
\hline \multicolumn{3}{c}{ Nationality } \\
\hline Saudi & 1560 & $52 \%$ \\
\hline American & 465 & $15.5 \%$ \\
\hline British & 348 & $11.6 \%$ \\
\hline
\end{tabular}

\begin{tabular}{lcc}
\hline & \multicolumn{2}{c}{ Number Percentage } \\
\hline Indian & 276 & $9.3 \%$ \\
\hline Pakistani & 219 & $7.3 \%$ \\
\hline Philipino & 129 & $4.3 \%$ \\
\hline \multicolumn{2}{c}{ Educational level } \\
\hline High School & 276 & $9.2 \%$ \\
\hline Diploma & 624 & $20.8 \%$ \\
\hline Bachelor & 1497 & $49.9 \%$ \\
\hline Master & 600 & $20 \%$ \\
\hline Doctorate & 3 & $0.1 \%$ \\
\hline
\end{tabular}

\begin{tabular}{ccc}
\hline \multicolumn{3}{c}{ Number Percentage } \\
\hline \multicolumn{3}{c}{ Years of Experience } \\
\hline Less than1 & 375 & $12.5 \%$ \\
\hline $1-5$ & 1275 & $42.5 \%$ \\
\hline $6-11$ & 918 & $30.6 \%$ \\
\hline 12 to 17 & 300 & $10 \%$ \\
\hline More than 17 & 132 & $4.4 \%$ \\
\hline \multicolumn{3}{c}{ Position level } \\
\hline Low & 1518 & $50.6 \%$ \\
\hline Middle & 1215 & $40.5 \%$ \\
\hline Top & 267 & $8.9 \%$ \\
\hline
\end{tabular}

\section{Testing Hypothesis}

Before testing the model, the underlying assumption was performed to ensure the resulted data met the statistical assumptions of simple linear regression analysis. These assumptions are: linearity, Errors are independent, Errors are normally distributed, and errors have a mean of zero homoscedasticity.

- Linearity. The researchers adopted a scatter plot (Figure 3) that gave a picture of the relationship between the two variables and assessed the correlation between them (Cohen et al, 2003). The points should be distributed along a straight line if the relationship is linear in the population (Cohen et al, 2003). An inspection of the bivariate scatterplots shows most of the points clustered along a straight line, so there were no linearity violations. 


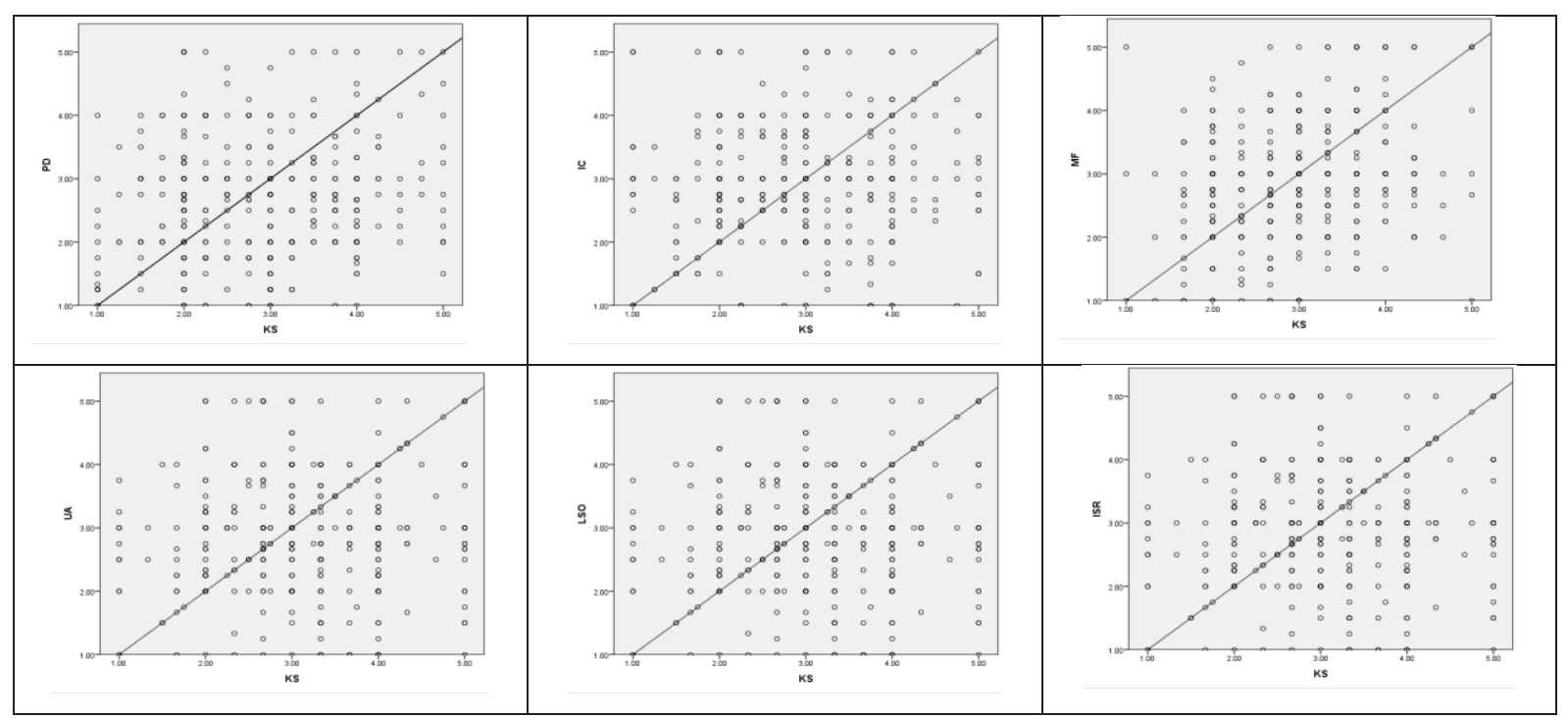

Figure 3: Linearity Assumption

- Errors are Independent. The independent assumption of errors assumes that the errors are un-correlated. This statistic can vary between 0 and 4 . The optimum value for this expectation to be fulfilled is close to 2 . Values below 1 and above 3 are cause for concern and may invalidate the research. Values between 0 and 2 are positive

Table No. (4)

Durbin Watson of the Independent Variables with Dependent Variables

\begin{tabular}{|c|c|c|c|c|c|}
\hline PD & IC & MF & UA & LSC & IS \\
\hline S 2.010 & 1.987 & 1.993 & 2.103 & 2.12 & \\
\hline
\end{tabular}
autocorrelation values, 2 are zero autocorrelation values, and values between 2 and 4 are negative autocorrelation values. Table 4 shows the value of Durbin Watson that lies between 1.987 to 2.012, which implies that this assumption has been fulfilled.

- Errors are Normally Distributed: The P-P plot (figure 4) used to test this assumption, which is a graphical technique for determining whether or not an error is distributed approximately normally. The closer the dots lie to the diagonal line, the more the errors are distributed closer to normal, as the figures below show that the expectation was met.

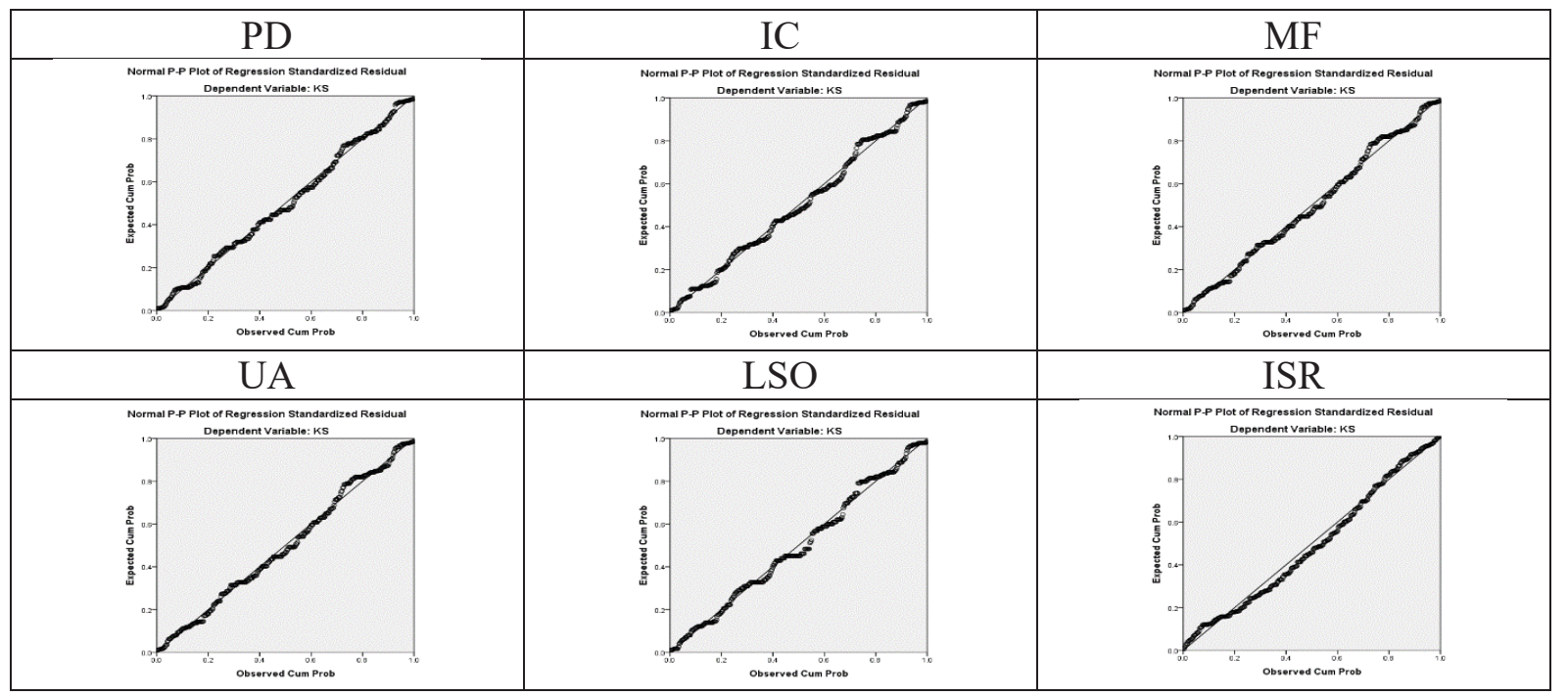

Figure 4: Assumption of Error Independency 
- Homoscedasticity: It means continuous variance of the errors, which implies that at all values of the other variable, the variability of scores for one variable is approximately the same. Cohen et al. (2003) argue that the conditional variance along the regression line of one variable's errors is believed to be constant. With bivariate scatterplots, the homoscedasticity assumption was checked and investigated for an oval shape (Green, 2016). Distribution along the line looks constant, and as the value of the variable increases, there is no right or left magnitude increase (figure 5). Consequently, there is evidence for an oval shape indicted constant variance of errors was met, and therefore the homoscedasticity assumption is met.

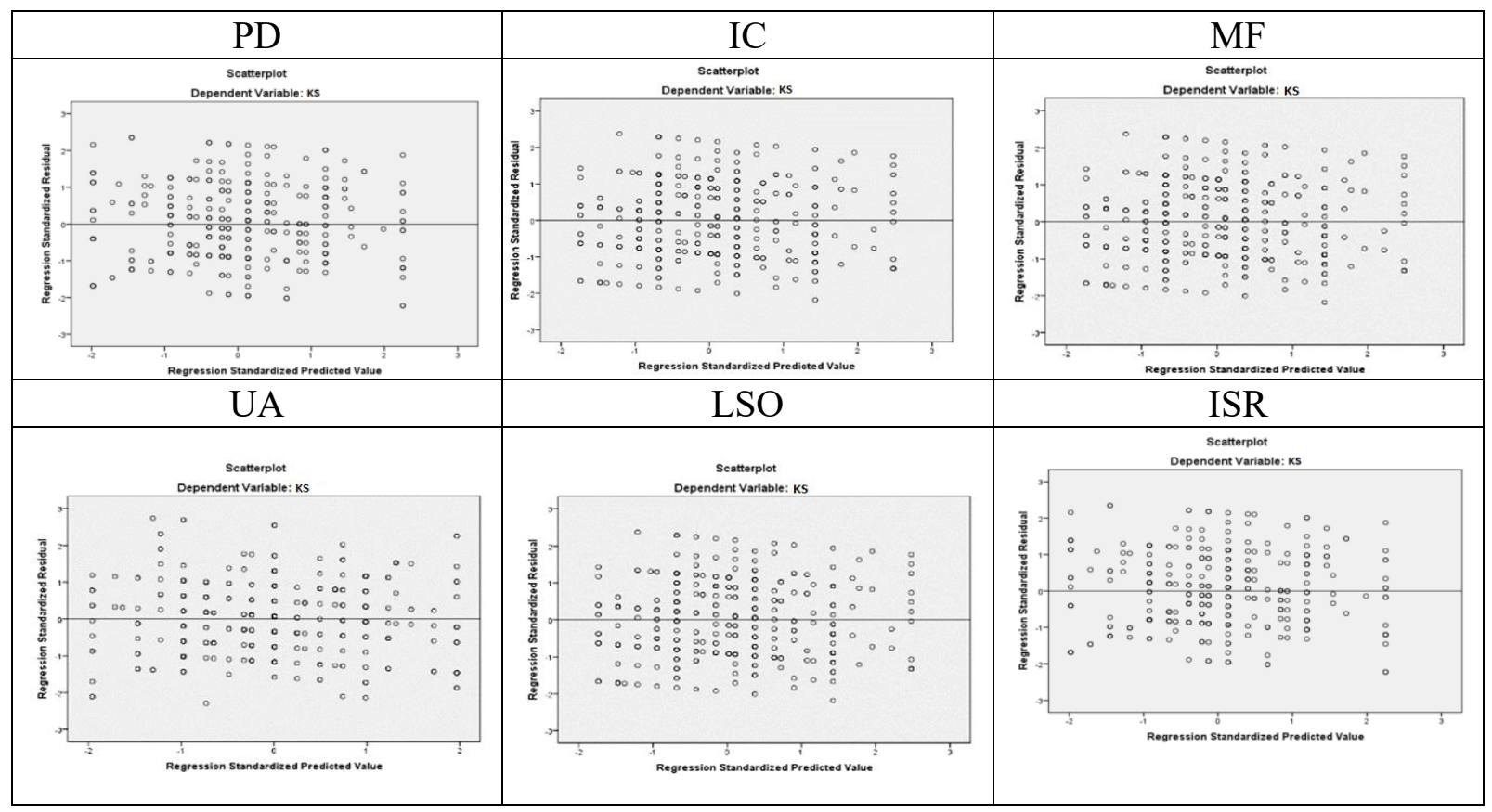

Figure 5: Assumption of Error Homoscedasticity

The simple linear regression used to examine the relationship between variables. The researchers are interested in testing the relationship between the PD, IC, MF, UA, LSO, ISR as independent variables and KS as a dependent variable.

Table 5 reveals a significant relationship between these variables. Regarding the relationship between $P D$ and $K S ; \beta=-0.330, t=3.675$ and $P=0.000<0.05$, $P<0.01, R=0.339$ and $11.6 \%$ of variability in $\mathrm{KS}$ is explained by PD. Therefore, there is a statistically significant negative relationship between PD and KS and $\mathrm{H} 1$ is not rejected.

In addition, In the relationship between Individualism and $\mathrm{KS} ; \beta=-0.352, \mathrm{t}=5.384$ and $\mathrm{P}=0.000<$ $0.05, \mathrm{P}<0.01, \mathrm{R}=0.405$ and $16.5 \%$ of variability in $\mathrm{KS}$ is explained by Individualism. Therefore, there is a statistically significant negative relationship between In-

Table No. (5)

Regression Analysis

\begin{tabular}{lcccccc}
\hline & & $\beta$ & $\mathbf{t}$ & $\mathbf{P}$ & $\mathbf{R}$ & $\mathbf{R}^{2}$ \\
\hline $\mathrm{H} 1$ & PD & -0.330 & 3.675 & 0.000 & 0.339 & 0.116 \\
\hline H2a Individualism & -0.352 & 5.384 & 0.000 & 0.405 & 0.165 \\
\hline H2b & Collectivism & 0.403 & 3.381 & 0.000 & 0.293 & 0.186 \\
\hline H3a & Masculinity & -0.328 & 4.469 & 0.000 & 0.168 & 0.125 \\
\hline H3b & Femininity & 0.428 & 3.470 & 0.000 & 0.121 & 0.135 \\
\hline $\mathrm{H} 4$ & UA & -0.546 & 5.430 & 0.000 & 0.231 & 0.146 \\
\hline H5a & LO & 0.552 & 3.389 & 0.000 & 0.324 & 0.225 \\
\hline H5b & SO & -0.521 & 3.378 & 0.000 & 0.312 & 0.335 \\
\hline H6a & Indulgence & -0.432 & 4.876 & 0.000 & 0.387 & 0.395 \\
\hline H6b & SR & 0.460 & 4.732 & 0.000 & 0.360 & 0.365 \\
\hline
\end{tabular}
dividualism and $\mathrm{KS}$ and $\mathrm{H} 2 \mathrm{a}$ is not rejected. In the relationship between Collectivism and $\mathrm{KS} ; \beta=0.403, \mathrm{t}=$ 3.381 and $\mathrm{P}=0.000<0.05, \mathrm{P}<0.01, \mathrm{R}=0.293$ and $18.6 \%$ of variability in $\mathrm{KS}$ is explained by Collectivism. Therefore, there is a statistically significant positive relationship between them and $\mathrm{H} 2 \mathrm{~b}$ is not rejected.

Moreover, In the relationship between Masculinity and $K S ; \beta=-0.328, t=4.469$ and $P=0.000<0.05$, $P<0.01, R=0.168$ and $12.5 \%$ of variability in KS is explained by Masculinity. Therefore, there is a statisti- 
cally significant negative relationship between them and $\mathrm{H} 3 \mathrm{a}$ is not rejected. In the relationship between Femininity and $K S ; \beta=0.428, t=3.470$ and $P=0.000<0.05, P<0.01, R=0.121$ and $13.5 \%$ of variability in $\mathrm{KS}$ is explained by Femininity. Therefore, there is a statistically significant positive relationship between them and $\mathrm{H} 3 \mathrm{~b}$ is not rejected.

Besides, In the relationship between $U A$ and $K S ; \beta=-0.546, t=5.430$ and $P=0.000<0.05, P<0.01, R$ $=0.231$ and $14.6 \%$ of variability in KS is explained by UA. Therefore, there is a statistically significant negative relationship between them and $\mathrm{H} 4$ is not rejected.

Additionally, In the relationship between LO and $\mathrm{KS} ; \beta=0.552, \mathrm{t}=3.389$ and $\mathrm{P}=0.000<0.05, \mathrm{P}<$ $0.01, R=0.324$ and $22.5 \%$ of variability in KS is explained by LO. Therefore, there is a statistically significant positive relationship between them and $\mathrm{H} 5 \mathrm{a}$ is not rejected. In the relationship between $\mathrm{SO}$ and $\mathrm{KS} ; \beta$ $=-0.521, \mathrm{t}=3.378$ and $\mathrm{P}=0.000<0.05, \mathrm{P}<0.01, \mathrm{R}=0.312$ and $33.5 \%$ of variability in $\mathrm{KS}$ is explained by $\mathrm{SO}$. Therefore, there is a statistically significant negative relationship between them and $\mathrm{H} 5 \mathrm{~b}$ is not rejected.

Finally, In the relationship between Indulgence and $K S ; \beta=-0.432, t=4.876$ and $P=0.000<0.05, P$ $<0.01, R=0.387$ and $39.5 \%$ of variability in KS is explained by Indulgence. Therefore, there is a statistically significant negative relationship between them and $\mathrm{H} 6 \mathrm{a}$ is not rejected. In the relationship between SR and $\mathrm{KS} ; \beta=0.460, \mathrm{t}=3.732$ and $\mathrm{P}=0.000<0.05, \mathrm{P}<0.01, \mathrm{R}=0.360$ and $36.5 \%$ of variability in $\mathrm{KS}$ is explained by SR. Therefore, there is a statistically significant positive relationship between them and $\mathrm{H} 6 \mathrm{~b}$ is not rejected.

To examine the moderate role of $\mathrm{OC}$ in the relationship between the PD, IC, MF, UA, LSO, ISR as independent variables and $\mathrm{KS}$ as a dependent variable, a process procedure for moderation analysis was conducted. Table 6 reveals the OC moderate and strength the relationship between (PD, $\mathrm{C}, \mathrm{F}, \mathrm{LO}, \mathrm{SR}$ ) and $\mathrm{KS}$. As shown in table 6, All of the statistical values are higher than the value without the moderate effect of OC. On the other hand, the OC moderate and weakness the relationship between $(\mathrm{I}, \mathrm{M}$, UA, SO, ID) and KS. Therefore, the relation-

Table No. (6)

The Moderate Role of OC

\begin{tabular}{|c|c|c|c|c|c|c|c|c|}
\hline & & $\bar{\beta}$ & $t$ & $\mathbf{P}$ & $\mathbf{R}$ & $\mathbf{R}^{2}$ & LLCI & ULCI \\
\hline $\mathrm{H1}$ & PD & -0.211 & 3.565 & 0.000 & 0.219 & 0.109 & 0.188 & 0.243 \\
\hline $\mathrm{H} 2 \mathrm{a}$ & Individualism & -0.219 & 5.213 & 0.000 & 0.295 & 0.124 & 0.165 & 0.220 \\
\hline $\mathrm{H} 2 \mathrm{~b}$ & Collectivism & 0.514 & 3.671 & 0.000 & 0.353 & 0.134 & 0.218 & 0.323 \\
\hline $\mathrm{H3a}$ & Masculinity & -0.209 & 4.899 & 0.000 & 0.108 & 0.171 & 0.235 & 0.440 \\
\hline $\mathrm{H} 3 \mathrm{~b}$ & Femininity & 0.578 & 3.120 & 0.000 & 0.251 & & 0.165 & 0.251 \\
\hline $\mathrm{H} 4$ & UA & -0.378 & 5.367 & 0.000 & 0.101 & 0.106 & 0.141 & 0.279 \\
\hline $\mathrm{H} 5 \mathrm{a}$ & $\mathrm{LO}$ & 0.698 & 3.781 & 0.000 & 0.454 & 0.215 & 0.224 & 0.335 \\
\hline $\mathrm{H} 5 \mathrm{~b}$ & $\mathrm{SO}$ & -0.328 & 3.221 & 0.000 & 0.112 & 0.205 & 0.250 & 0.471 \\
\hline $\mathrm{H} 6 \mathrm{a}$ & Indulgence & -0.245 & 4.257 & 0.000 & 0.267 & 0.175 & 0.211 & 0.343 \\
\hline $\mathrm{H} 6 \mathrm{~b}$ & SR & 0.587 & 4.581 & 0.000 & 0.490 & 0.285 & 0.242 & 0.480 \\
\hline
\end{tabular}
ship between all independent variables and KS is moderated by $\mathrm{OC}$ and $\mathrm{H} 7$ is supported.

Figure 6 shows the comparison result between nationalities understudy in this paper with original Hofstede index for nationalities. The resulted comparison is almost near the Hofstede index for these nationalities.

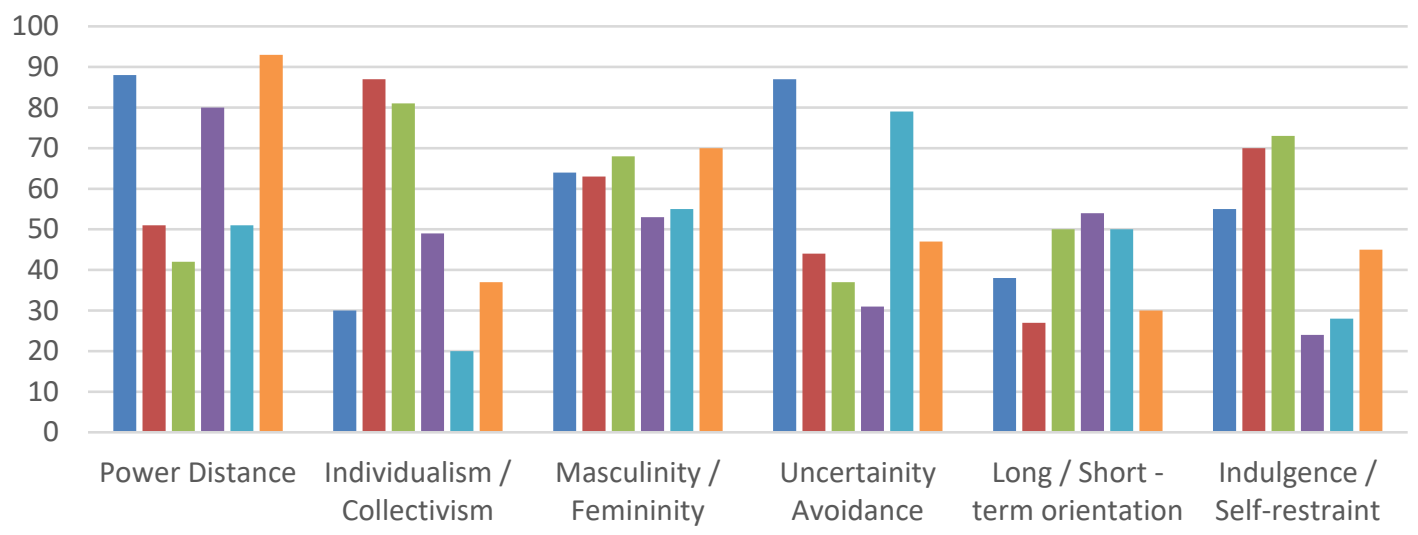

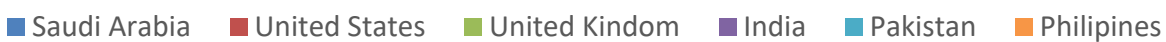

Source: Developed by authors

Figure 6: National Culture Index of the Sample Understudy 


\section{DISCUSSION}

This study aims to examine the impact of national culture based on Hofstede's concept of cultural dimensions on knowledge sharing and the moderate role of the organizational culture as success factors. Seven hypotheses have been developed to achieve this objective. All of these hypotheses are supported; Collectivism, Femininity, LO, and SR positively impact KS, while PD, I, M, UA, SO, and ID negatively impact the KS. Moreover, OC play a moderate role as a success factor to maximize the advantage of PD, C, F, LO, and SR and minimize the impact of I, M, UA, SO, and ID on KS. In addition, the index of six national cultural dimensions of the sample under study was compared to the original Hofstede index and resulted in almost the same values.

PD has a significant negative impact on $\mathrm{KS}$, which may appear in such an organization as a very distinct hierarchical line that is not allowed to be bypassed, forces juniors to follow superiors, not discuss with them freely, and give the superior the last word. This finding agreed with Wang et al. (2011), Evans et al. (2014), and Jang et al. (2016).

Individualism has a significant negative impact on KS that may appear in willingness to stand against group members, considering personal value as more significant than community objectives, preferring competition over cooperation, rarely share and interchange knowledge, and therefore limiting organizational ability to share knowledge. This finding agreed with Bochner \& Hesketh (1994), hin et al. (1998), Nahapet \& Ghushal (1998), and Smeth et al. (2005). On the other hand, Collectivism has a significant positive impact on KS. It might emphasize cooperation and collective effort, believe in jointly responsible for the successes and failures, and prefer close collaboration with colleagues over working independently. Many previous studies agreed with this result, such as Chen et al. (1998), Witherspoon et al. (2013), Nahapiet \& Ghoshal (1998), Wagner (1995), Fathi et al. (2011), Yu (2014), Wiang et al. (2011), and Qin et al. (2011).

Regarding the impact of masculinity on KS, as resulted by this study, it is a negative impact might appear as competition not cooperation relationship between coworkers, standing out from coworkers. It reveals society's attitude toward doing and being, gender domination, and the imbalanced distribution of roles between men and women. This finding agreed with Evans, et al. (2014), and Ford and Chan (2003). On the other hand, femininity has s positive impact on KS, which means that the community's principal values are taking care of others and life quality. It also means that the life quality is the mark of success, and standing out from the crowd is not preferable that agreed with the finding of Hofstede (2001), and Hofstede (2010).

UA has a negative impact on KS, where the organization has strict regulations and procedures that classify and monitor its organizational duties and rights. Members are reluctant to take risks, hesitating to solve problems creatively, restrictive, persistent to change, and have low innovation levels due to their reliance on rules and regulations. This result is agreed with the finding of Efrat (2014), Garrett, et al. (2006), and House et al. (2004).

Long-term orientation or high Confucian dynamism is characterized by persistence, following a specific ordering pattern, proclivity for thinking about the future, perseverance, placing an order for relationships based on status, thrifty values, and having a feeling of shame. In contrast, Members of short-term orientation or low Confucian dynamism scores respect the relative importance of the past and present, such as personal constancy and steadiness, saving face, respect for custom and tradition, and reciprocation of greetings and favors and gifts. Based on the result of this study, long-term orientation has a positive impact on $\mathrm{KS}$, while short-term orientation has a negative impact on $\mathrm{KS}$, and these are agreed with the findings of Ford and Chan (2003), and Evans, et al. (2014).

Indulgence represents a tolerance of the human drives' natural wants and needs related to enjoying life and having fun. Self-Restraint, on the other hand, prohibits an open gratification of desires and regulates 
it through strict social norms and traits. The result of this study asserts the earlier arguments that indulgence has a negative impact on KS while self-restraint has a positive impact. The studying for this factor considered as a contribution in the field because the lack of studies that deal with it.

The Five major factors that make up this study's organizational culture are confidence, employees' communication, information systems, incentives system, and organizational structure. The result of this study asserts the earlier argument that indicates the organizational culture minimize the negative impact of national culture on knowledge sharing and maximize their impact as well and agreed with the findings of Al Alawi, et al. (2007), Politis (2003), Gruenfeld et al. (1996), Smeth \& Rupp (2002), Whiten et al. (2001), Connelly \& Kelloway (2003), Syed-lkhsan \& Rowland (2004), and Goh (2002).

This research helped to enhanced the literature of knowledge management by allowing researchers to illustrate the national cultural characteristics that lead to an assessment of their influence on knowledge sharing. The impact of the organizational culture as moderate in the relationship between national culture dimensions and knowledge sharing was contributed in this study.

\section{CONCLUSION AND MANAGERIAL IMPLICATION}

In February (2021), the Saudi government announced its intention to stop contracting with any foreign company or commercial institution that has a regional headquarters outside Saudi Arabia, starting from (1/1/2024AD). Later, 24 international companies signed agreements to establish main regional offices in Riyadh (SPA, 2020). This action will increase the diversity of nationalities within these organizations, in addition to the current national diversity in local and international companies that have branches before this announcement, which increases the importance of the dimensions of national cultures on organizations as an impact factor on KS within organizations as it found by this study.

Organizations should take appropriate action that aims to maximize the positive impact of (Collectivism, Femininity, LO, and SR) factors and minimize the negative impact of (PD, Individualism, Masculinity, $\mathrm{UA}, \mathrm{SO}$, Indulgence) factors. The results of this study showed the importance of organizational culture in this regard.

Personal trust or trust between employees has a great impact on knowledge sharing. Because this, the organizations must enhance trust among employees by offering incentives for desirable ethical practices such as honesty, integrity and respect. It is suggested that the organization develop a code of professional ethics and distribute it periodically, send collective messages and distribute encouragement phrases for these ethics in separate places within the organization. Senior management's adherence to these practices can have a strong positive effect on achieving this goal.

The organization should also enhance human interaction among employees by encouraging positive verbal and nonverbal discussions in addition to emphasizing the importance of body language in this aspect. The presence of social networks within the organization greatly enhances this human interaction. These networks can be activated by organizing periodic meetings between employees outside the framework of work in which good employees are honored, and friendly relations are strengthened between them.

Information systems facilitate daily organizational processes, problem solving, and decision making by using different information systems that encourage KS by creating or acquiring knowledge repositories, where employees physically or digitally share experience and other employees gain access to shared knowledge. Therefore, the organization must focus on this aspect and take the necessary administrative actions for it.

Employees need strong incentives to share knowledge because it is unlikely that all employees will easily share their knowledge without thinking about the gains or losses of their actions. Therefore, the or- 
ganization must design appropriate incentive systems, recognize the importance of cooperation between employees, and the exchange of best practices. The point is to have an incentive system that promotes and rewards knowledge sharing and horizontal communication.

The complex layers and lines of responsibility in the bureaucratic hierarchy are characteristic of traditional organizations due to their many drawbacks in slowing down processes, restricting data flow, and thus knowledge sharing. Therefore, the organization must modify and develop its organizational structure in proportion to facilitating the information flow between departments and among employees from different nationalities. The de-concentration of nationalities within each department can have the positive impact that enhancing knowledge sharing.

\section{LIMITATION AND FUTURE RESEARCH}

The main limitation for this study is its sampling design "simple random sampling" that has major disadvantages in its inability to generalize the results at all (Sekaran and Bougie, 2016).

Future research is suggested to be conducted in other local, regional, or global communities or companies to compare the phenomenon under study with this study's result. Finally, future research may add mediate and \or different moderate variables to assess whether they play a role between variables. 


\section{REFERENCE}

Akar, N. D. and Ertu” rk, A. (2010). “Comparing innovation capability of small and medium-sized enterprises: examining the effects of organizational culture and empowerment", Journal of Small Business Management, 48 (3), pp. 325-359.

- $\quad$ Al Hawamdeh, N. \& Al Qatamin, A. (2021). "The effect of cultural dimensions on knowledge-sharing intentions: Evidence from higher education institutions in Jordan", The Journal of Asian Finance, Economics and Business, 8(5), 1079-1089.

- Al-Alawi, A. I.; Al-Marzooqi, N. Y. \& Mohammed, Y. F. (2007). “Organizational culture and knowledge sharing: critical success factors", Journal of Knowledge Management, 11 (2), pp. 22-42.

- $\quad$ Bates, K. A.; Amundson, S. D.; Schroeder, R. G. and Morris, W. T. (1995). "The crucial interrelationship between manufacturing strategy and organizational culture", Management Science. 41, (10), pp. 1565-1580.

- $\quad$ Bearden, W. O.; Money, R. B. \& Nevins, J. L. (2006). “A measure of long-term orientation: Development and validation", Journal of the Academy of Marketing Science, 34 (3), pp. 456-467.

- $\quad$ Bhagat, R. S.; McDevitt, A. S.; McDevitt, I. (2009). “Cultural variations in the creation, diffusion and transfer of organizational knowledge", In Bhagat, R. and Steers, R. M. (Eds.), Cambridge Handbook of Culture, Organizations and Work, Cambridge, Cambridge University Press, pp. 174-193.

- Bochner, S. and Hesketh, B. (1994). “Power distance, individualism/collectivism, and job-related attitudes in a culturally diverse work group", Journal of Cross-Cultural Psychology, 25 (2), pp. 233-57.

- $\quad$ Cabrera, A. \& Cabrera, E. F. (2002). “Knowledge-sharing dilemmas”, Organization Studies, 23 (5), pp. 687-710.

- Cantwell, J. (2000). A survey of theories of international production. London: Routledge

- Chen, C. C.; Chen, X. P. and Meindl, J. R. (1998), "How can cooperation be fostered? The cultural effects of individualism-collectivism", Academy of Management Review, 23 (2), pp. 285-304.

- $\quad$ Ciborra, C. U. \& Patriotta, G. (1998). “Groupware and teamwork in R \& D: Limits to learning and innovation. $\boldsymbol{R} \& \boldsymbol{D}$ Management, 28(1), pp. 43-52.

- Connelly, C. and Kelloway, E. (2003). “Predictors of employees' perceptions of knowledge sharing cultures", Leadership \& Organization Development Journal, 24 (5), pp. 294-301.

- Dalkir, K. (2017). Knowledge management in theory and practice. MIT press.

- Dimitratos, P.; Petrou, A.; Plakoyiannaki, E. and Johnson, J. E. (2011). "Strategic decision-making processes in internationalization: Does national culture of the focal firm matter?", Journal of World Business, 46 (2), pp. 194-204.

- Efrat, K. (2014). "The direct and indirect impact of culture on innovation", Technovation, 34 (1), pp. $12-20$

- $\quad$ Engelen, A.; Brettel, M. and Wiest, G. (2012). “Cross-functional integration and new product performance - The impact of national and corporate culture", Journal of International Management, 18 (1), pp. 52-65

- $\quad$ Erramilli, M. K. (1996). "Nationality and subsidiary ownership patterns in multinational corporations", Journal of International Business Studies, 27 (2), pp. 225-248.

- $\quad$ Evans, C.; Hackney, R. \& Ray, D. (2014). “Overcoming cross-cultural barriers to knowledge management using social media", Journal of Enterprise Information Management. 
Fathi, N.; Cyril Eze, U. \& Guan Gan Goh, G. (2011). “Key determinants of knowledge sharing in an electronics manufacturing firm in Malaysia", Library Review, 60 (1), pp. 53-67.

- Ford, D. P. \& Chan, Y. E. (2003). "Knowledge sharing in a multi-cultural setting: A case study", Knowledge Management Research and Practice, 1 (1), pp. 11-27.

- Garrett, T. C.; Buisson, D. H. and Yap, C. M. (2006). “National culture and R\&D and marketing integration mechanisms in new product development: A cross-cultural study between Singapore and New Zealand", Industrial Marketing Management, 35 (3), pp. 293-307.

- Goh, S. (2002). "Managing effective knowledge transfer: an integrative framework and some practice implications", Journal of Knowledge Management, 6 (1), pp. 23-30.

- Griffith, D. A.; Zhang, C. and Cavusgil, S. T. (2006). "Attributions of non-cooperative incidents and response strategies: The role of national character", Journal of World Business, 41 (4), pp. 356-367.

- Gruenfeld, D.H.; Mannix, E. A.; Williams, K. Y. and Neale, M. A. (1996). “Group composition and decision making: how member familiarity and information distribution affect process and performance", Organizational Behavior and Human Decision Process, 67 (1), pp. 1-15.

- Gupta, A. K. and Govindarajan, V. (2000). “Knowledge management social dimension: lessons from Nucor Steel", Sloan Management Review, 42 (1), pp. 71-81.

- Hall, E. T.; Hall, M. R. (1990). Understanding cultural differences, Intercultural Press Inc., Yarmouth.

- Hauff, S.; Richter, N. F. and Tressin, T. (2015). "Situational job characteristics and job satisfaction: The moderating role of national culture", International Business Review, 24 (4), pp. 710-723.

- Hofstede, G. (2001). Culture's Consequences: comparing values, behaviors, institutions, and organizations across nations, Thousand Oaks, CA., Sage.

- Hofstede. (2010). Cultures and organizations: Software of the mind, intercultural cooperation and its importance for survival. $3^{\text {rd }}$ Revised Edition. McGraw-Hill.

Hofstede. G. \& Hofstede, G. J. (2005). Cultures and organizations: Software of the mind. (2 ${ }^{\text {nd }}$ ed). New York: McGraw-Hill

Hofstede Insights. (2021). Compare countries, Retrieved 16 February 2021, from https://www. hofstede-insights.com/product/compare-countries/

- Homburg, C. and Jensen, O. (2007). “The thought worlds of marketing and sales: Which differences make a difference?", Journal of Marketing, 71 (3), pp. 124-142.

- House, R. J.; Hanges, P. J.; Javidan, M.; Dorfman, P. W. \& Gupta, V. (2004). Culture, leadership and organizations: The GLOBE study of 62 societies. Sage Publications.

- Hussien, S. \& Khedr, W. (2021). "The effect of national culture on knowledge sharing: Empirical study on university students in UK", Arab Journal for Administration, 41 (1), pp. 369-388.

- Ipe, M. (2003). "Knowledge sharing in organizations: A conceptual framework", Human Resource Development Review, 2 (4), pp. 337-359.

- Janićijević, N. (2016). “National culture and organizational learning”, In: 2016 ENTRENOVA Conference Proceedings.

- Javidan, M.; Dorfman, P. W.; de Luque, M. S. and House, R. J. (2006). "In the eye of the beholder: Cross cultural lessons in leadership from project GLOBE", Academy of Management Perspectives, Vol.20, No.1, pp. 67-90.

- $\quad$ Jiang, L. \& Probst, T. M. (2016). "Transformational and passive leadership as cross-level moderators of the relationships between safety knowledge, safety motivation and safety participation", Journal of Safety Research, 57, pp. 27-32. 
Jones, G. K. and Davis, H. J. (2000). “National culture and innovation: Implications for locating global R\& D operations", Management International Review, 40 (1), pp. 11-39.

- $\quad$ Liebowitz, J. (Ed.). (1999). Knowledge management handbook. CRC Press.

- Matsudaira, T.; Fukuhara, T. \& Kitamura, T. (2008). “Factor structure of the Japanese interpersonal competence scale", Psychiatry and Clinical Neurosciences, 62 (2), pp. 142-151.

- McDermott, R. and O'Dell, C. (2001). "Overcoming cultural barriers to sharing knowledge", Journal of Knowledge Management, 5 (1), pp. 76-85.

- Mihet, R. (2013). "Effects of culture on firm risk-taking: A cross-country and cross-industry analysis", Journal of Cultural Economics, 37 (1), pp. 109-151.

- Miller, D. \& Shamsie, J. (1996). "The resource-based view of the firm in two environments: The Hollywood film studios from 1936 to 1965", Academy of Management Journal, 39 (3), pp. 519-543.

- Miller, D. L. \& Karakowsky, L. (2005). “Gender influences as an impediment to knowledge sharing: When men and women fail to seek peer feedback", The Journal of Psychology, 139 (2), pp. 101-118.

- Nahapiet, J. and Ghoshal, S. (1998), "Social capital, intellectual capital, and the organizational advantage", Academy of Management Review, 23 (2), pp. 242-266.

- Olson, E. M.; Walker, O.; Ruekert, R. and Bonner, J. (2001). “Patterns of cooperation during new product development among marketing, operations and R \& D: Implications for project performance", Journal of Product Innovation Management, 18 (4), pp. 258-271.

- Park, H.; Ribiere, V. and Schulte, W. (2004). “Critical attributes of organizational culture that promote knowledge management implementation success", Journal of Knowledge Management, 8 , (3), pp. 106-117.

- Politis, J. (2003). “The connection between trust and knowledge management: what are its implications for team performance", Journal of Knowledge Management, 7 (5), pp. 55-66.

- $\quad$ Qin, C.; Ramburuth, P. and Wang, Y. (2011). “A conceptual model of cultural distance, MNC subsidiary roles, and knowledge transfer in China-based subsidiaries", Organizations and Markets in Emerging Economies, Vol. 2, No. 2, pp. 8-27.

- $\quad$ Reinhardt R.; Boremann M.; Pawlovsky P.; Schneider U. (2003). “Intelectual capital and knowledge management: Perspectives on measuring Knowledge", In Dierkes, M., Berthoin, A. A., Child, J., Nonaka, I. (Eds.) Handbook of Organizational Learning \& Knowledge. Oxford, Oxford University Press, pp. 794-823.

- $\quad$ Robert, C.; Probst, T. M.; Martocchio, J. J.; Drasgow, F. and Lawler, J. J. (2000). “Empowerment and continuous improvement in the United States, Mexico, Poland and India: Predicting fit on the basis of the dimensions of power distance and individualism", Journal of Applied Psychology, 85 (5), pp. 643-658.

- Saudi Press Agency (SPA). (2021). Suspension of contracting with any foreign commercial company or establishment with a regional headquarters in the region outside the Kingdom. Retrieved 24 February 2021, from https://www.spa.gov.sa/2191780.

- Schwartz, S. H. (1992). "Universals in the Content and structure of values: Theoretical advances and empirical tests in 20 countries", in Zanna, M.P. (Ed.) Advances in Experimental Social Psychology, San Diego, Academic Press, pp. 1-65.

- $\quad$ Sekaran, U. \& Bougie, R. (2016). Research methods for business: A skill building approach. $7^{\text {th }}$ ed. United Kingdom: John Wiley \& Sons. 
Serban, A. M. \& Luan, J. (2002). “Overview of knowledge management", New Directions for Institutional Research, 2002 (113), pp. 5-16.

- $\quad$ Siau, K.; Erickson, J. \& Nah, F. F. H. (2010). “Effects of national culture on types of knowledge sharing in virtual communities", IEEE Transactions on Professional Communication, 53 (3), pp. 278-292.

- $\quad$ Sinha, J. B. \& Sinha, D. (1990). “Role of social values in Indian organizations", International Journal of Psychology, 25(3-6), pp. 705-714.

- Smith, A. and Rupp, W. (2002). “Communication and loyalty among knowledge workers: a resource of the firm theory view", Journal of Knowledge Management, 6 (3), pp. 250-261.

- Smith, K. G.; Collins, C. J. and Clark, K. D. (2005). "Existing knowledge, knowledge creation capability, and the rate of new product introduction in high-technology firms", Academy of Management Journal, 48 (2), pp. 346-357.

- $\quad$ Syed-Ikhsan, S. and Rowland, F. (2004). “Knowledge management in public organizations: a study on the relationship between organizational elements and the performance of knowledge transfer", Journal of Knowledge Management, 8 (2), pp. 95-111.

- Tihanyi, L.; Griffith, D. A. and Russell, C. J. (2005). "The effect of cultural distance on entry mode choice, international diversification, and MNE performance: A meta-analysis", Journal of International Business Studies, 36 (3), pp. 270-283.

- Trompenaars, F. (1994). Riding waves of culture: Understanding diversity in global business. New York, McGraw Hill.

- Troy, L. C.; Hirunyawipada, T. and Paswan, A. K. (2008). “Cross-functional integration and new product success: An empirical investigation of the findings", Journal of Marketing, 72 (6), pp. 132-146.

- Wagner, J. A. III (1995). "Studies of individualism-collectivism: effects on cooperation", Academy of Management Journal, 38 (1), pp. 152-172.

- Wang, D.; Su, Z. \& Yang, D. (2011). “Organizational culture and knowledge creation capability”, Journal of Knowledge Management., 15 (3), pp. 363-373.

- Whitten, J.; Bentley, L. and Dittman, K. (2001). System Analysis and Design Methods. McGraw-Hill, New York, NY.

- Witherspoon, C. L.; Bergner, J.; Cockrell, C. \& Stone, D. N. (2013). "Antecedents of organizational knowledge sharing: A meta-analysis and critique", Journal of Knowledge Management, 17 (2), pp. 250-277.

- Yu, M. (2014). "Examining the effect of individualism and collectivism on knowledge sharing intention: an examination of tacit knowledge as moderator", Chinese Management Studies, 8 (1), pp. 149-166.

- Zaim, H.; Keceli, Y.; Jaradat, A. \& Kastrati, S. (2018). “The effects of knowledge management processes on human resource management: Mediating role of knowledge utilization", Journal of Science and Technology Policy Management, 9, pp. 310-328. 